Article

\title{
Antiprotozoal Activity of Triazole Derivatives of Dehydroabietic Acid and Oleanolic Acid
}

\author{
Mariano Walter Pertino ${ }^{1, *}$, Celeste Vega ${ }^{2}$, Miriam Rolón ${ }^{2}$, Cathia Coronel ${ }^{2}$, \\ Antonieta Rojas de Arias ${ }^{2}$ and Guillermo Schmeda-Hirschmann ${ }^{1}$ \\ 1 Laboratorio de Química de Productos Naturales, Instituto de Química de Recursos Naturales, \\ Universidad de Talca, 3460000 Talca, Chile; schmeda@utalca.cl \\ 2 Centro para el Desarrollo de la Investigación Científica (CEDIC), Manduvirá 635 entre 15 de Agosto y \\ O’Leary, Barrio La Encarnación 1255, 2511 Asunción, Paraguay; mcvegagomez@gmail.com (C.V.); \\ rolonmiriam@gmail.com (M.R.); cathiacoronel@gmail.com (C.C.); rojasdearias@gmail.com (A.R.d.A.) \\ * Correspondence: mwalter@utalca.cl; Tel.: +56-71-2418866
}

Academic Editor: Jean-Marc Sabatier

Received: 23 January 2017; Accepted: 21 February 2017; Published: 28 February 2017

\begin{abstract}
Tropical parasitic diseases such as Chagas disease and leishmaniasis are considered a major public health problem affecting hundreds of millions of people worldwide. As the drugs currently used to treat these diseases have several disadvantages and side effects, there is an urgent need for new drugs with better selectivity and less toxicity. Structural modifications of naturally occurring and synthetic compounds using click chemistry have enabled access to derivatives with promising antiparasitic activity. The antiprotozoal activity of the terpenes dehydroabietic acid, dehydroabietinol, oleanolic acid, and 34 synthetic derivatives were evaluated against epimastigote forms of Trypanosoma cruzi and promastigotes of Leishmaniabraziliensis and Leishmania infantum. The cytotoxicity of the compounds was assessed on NCTC-Clone 929 cells. The activity of the compounds was moderate and the antiparasitic effect was associated with the linker length between the diterpene and the triazole in dehydroabietinol derivatives. For the oleanolic acid derivatives, a free carboxylic acid function led to better antiparasitic activity.
\end{abstract}

Keywords: cytotoxicity; dehydroabietic acid; Leishmania spp.; oleanolic acid; triazole derivatives; Trypanosoma cruzi

\section{Introduction}

Chagas is endemic in 21 countries in Latin America. It is a zoonotic parasitosis considered one of the most important neglected diseases in Latin America with a total of 520,043 DALYs (years of disability-adjusted life) [1-4]. Currently, it was estimated that 90-100 million people are at risk of contracting Chagas disease and eight million are infected by the flagellate protozoan Trypanosoma cruzi with approximately 12,000 deaths and 56,000 new cases per year [5]. An estimated 5.4 million people will develop cardiac Chagas disease [1,6], while 900,000 will have megaesophagus and megacolon [1]. Given the globalization of our days, the disease exists in at least 10 non-endemic countries. Currently, more than two million people infected with Chagas disease live in Spain and other European countries [7], and even in other continents [8].

There are two phases of Chagas disease. The first acute phase last around four months and is characterized by large numbers of parasites circulating in the patient blood. However, just $5 \%$ of patients are detected during the acute phase and can be cured [9]. In the chronic phase, the parasitemia is low, and the pathognomonic manifestation could appear as chronic cardiomyopathy, megas in the digestive tract, as well as damage to the central nervous system. Two major groups of the T. cruzi parasite strains have been described elsewhere (TcI and TcII). TcI is associated with the sylvatic cycle of 
transmission while TcII is associated with the domestic cycle [10,11]. It was observed that a specific geographical distribution of these two major groups. TcI strains predominate in the Amazon basin and the northern countries of South America, Central America, and Mexico, while TcII is commonly found in the southern part of South America. The megas are usually found in the south. By this fact, TcII strains are incriminated as more pathogenic than TcI strains [11].

Chances of being cured in the chronic phase, by conventional treatments, are very low. This disease is considered, together with leishmaniasis and African Trypanosomiasis, an extremely neglected disease. In the case of the poorest countries in the developing world, they are characterized by the fact that they affect poor populations in developing countries, which do not add services, being excluded socioeconomically and, consequently, pharmaceutical markets [12].

Leishmaniasis is generally endemic in 98 countries and territories in the world, and is responsible for a disease burden of 2.35 million DALYs, $2.3 \%$ of which occur in the Americas $(50,668)$ [4]. More than 12 million people are infected with leishmaniasis, and 350 million are at risk. It is estimated that $75 \%$ of all cases of cutaneous leishmaniasis are concentrated in 10 countries, four of which are in the Americas: Brazil, Colombia, Peru, and Nicaragua. Brazil is one of the six countries where $90 \%$ of the cases of visceral leishmaniasis have been found; the others are Ethiopia, India, Bangladesh, Sudan, and South Sudan. In the Americas, an average of 60,000 cases of cutaneous and mucosal leishmaniasis and 4000 cases of visceral leishmaniasis are diagnosed each year, with a mortality rate of $7 \%[13,14]$.

One of the most widely distributed species in Latin America is Leishmania braziliensis that can produce both cutaneous and mucocutaneous leishmaniasis. Another important species is L. infantum that can produce visceral leishmaniasis, the most common species identified in animals especially dogs [15]. These two species were selected to perform the in vitro leishmanicidal activity of the compounds tested in this study. The life cycle of both parasites spends an important development inside the reservoir or in the human body. The trypomastigote forms of T. cruzi enter the organism through the skin or mucous membranes, then pass into the cells of the endothelial reticulum or into the circulatory or lymphatic torrent $[16,17]$. When the parasite enters the cells, it is transformed into amastigotes, which multiply until it completely invades the cell and becomes epimastigotes. Afterwards, the cell in the trypomastigotes is broken, and the trypomastigotes are released into the circulatory torrent. At this moment, the trypomastigotes can be detected by a fresh examination, and they later invade new tissues and become amastigotes, thus closing the cycle. A similar cycle is observed in Leishmania spp. Promastigotes are phagocytized by macrophages and other types of mononuclear phagocytic cells, and transformation allows them to reach amastigotes, the tissue stage of the parasite, which multiply by simple division and proceed to infect other mononuclear phagocytic cells $[18,19]$.

The promastigotes and epimastigotes are the extracellular dividing forms of the parasite inside the insect vectors of Leishmania spp. and T. cruzi, respectively. As they are easy to cultivate under laboratory conditions, these models are a good choice for preliminary in vitro screening [20,21].

Despite the progress in the chemotherapy of the mentioned parasitic diseases, there is an urgent need for new drugs. Although Chagas disease can be treated with drugs such as nifurtimox and benznidazole, there are reports on which these treatments fail [22]. The drugs currently used by leishmaniasis have discreet effectiveness, long treatment times, high cost, and adverse effects, and the parasites rapidly develop resistance to drugs [23]. Therefore, the discovery of new drugs is a priority. Just $3.8 \%$ of drugs approved between 2000 and 2011 were for neglected diseases such as leishmaniasis, Chagas disease, and sleeping sickness, which together represent more than $10 \%$ of the global burden of diseases [24].

Several natural products of plants such as phenolic, alkaloids, saponins, and terpenes show potent and selective bioactivity for the treatment of tropical diseases [25]. Abietane-type diterpenes isolated from roots of Salvia cilicica (Lamiaceae), and triterpenes such as ursolic acid and betulinaldehyde, display significant in vitro antileishmanial activity. Recently, different research groups have used the $\mathrm{Cu}(\mathrm{I})$ catalyzed 1,3-dipolar-cycloaddition reaction of azide and alkyne (CuAAC) 
to generated 1,2,3-triazoles on the search for antiparasitic drugs. Using this reaction, they obtained triazol-derivatives of sugars, benznidazoles, naphthoquinones, and sterols with excellent antiparasitic properties [26-30]. In previous work, we reported the synthesis and antiproliferative activity of dehydroabietic acid (DHA) coupled with 1,2,3-triazoles (1-16) and 1,2,3-triazole-substituted oleanolic acid (OA) derivatives (17-34). Most of the compounds showed low antiproliferative activity on tumor and normal cells. Therefore, they should be regarded as compounds with low toxicity, which can be an advantage when looking for selective drugs [20]. In the present work, compounds 1-34 were examined for a trypanocidal effect on T. cruzi and in vitro activity against two promastigote stages of Leishmania spp.

\section{Results and Discussion}

From the starting terpenes OA, DHA, and dehydroabietinol, 34 synthetic derivatives were prepared (Figure 1) and assessed against epimastigote forms of T. cruzi, promastigotes from Leishmania spp. as well as for cytotoxicity. The results are summarized in Table 1.<smiles>[R]OC(=O)[C@]1(C)CCC[C@]2(C)c3ccc(C(C)C)cc3CC[C@H]21</smiles>

n:1 R: Phenyl

$\mathrm{n}: 2 \quad \mathrm{R}:$ Phenyl

$\mathrm{n}: 1 \quad \mathrm{R}:$ methyl phenyl sulfide

$\mathrm{n}: 2 \quad \mathrm{R}$ : methyl phenyl sulfide<smiles>[Y9]C(Cc1cn([R])nn1)C(=O)OC[C@@]1(C)CCC[C@@]2(C)c3ccc(C(C)C)cc3CC[C@H]12</smiles>

5 n:1 R: Phenyl

6 n:3 R: Phenyl

7 n:1 R: Benzyl

8 n:3 R:Benzyl

9 n:1 R: Methyl phenyl sulfide

10 n:3 R: Methyl phenyl sulfide

11 n:1 R: $p$-anisidyl

12 n:3 R: $p$-anisidyl

13 n:1 R: $m$-Chlorobenzyl

14 n:3 R: $m$-Chlorobenzyl

$15 \mathrm{n}: 1 \quad \mathrm{R}: p$-toluenesulfonyl

16 n:3 R: $p$-toluenesulfonyl

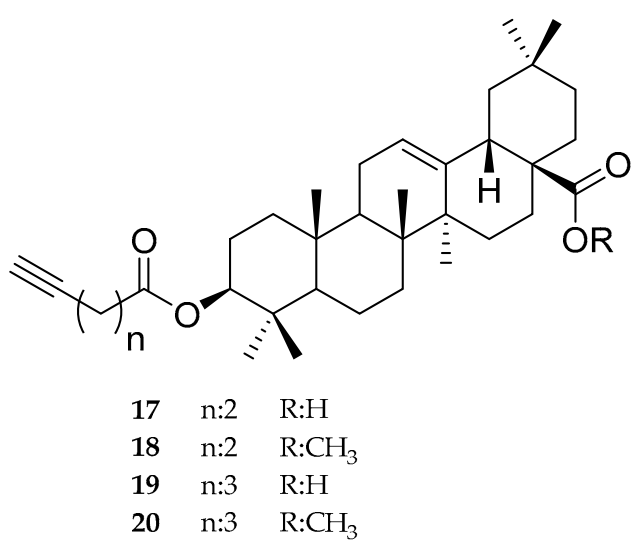

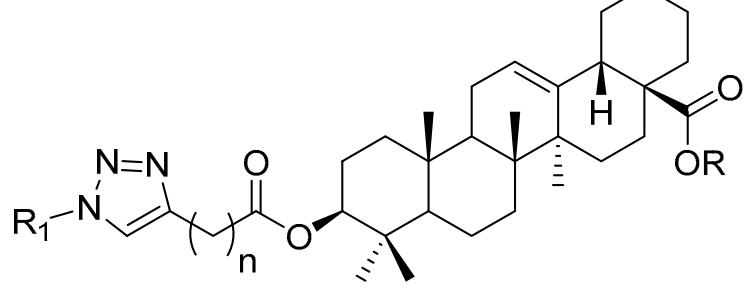

\begin{tabular}{|c|c|c|c|}
\hline 21 & $\mathrm{n}: 2$ & $\mathrm{R}: \mathrm{H}$ & $\mathrm{R}_{1}$ : Phenyl \\
\hline 22 & $\mathrm{n}: 2$ & $\mathrm{R}: \mathrm{CH}_{3}$ & $\mathrm{R}_{1}$ : Phenyl \\
\hline 23 & $\mathrm{n}: 2$ & $\mathrm{R}: \mathrm{H}$ & $\mathrm{R}_{1}: p$-anisidyl \\
\hline 24 & $\mathrm{n}: 2$ & $\mathrm{R}: \mathrm{CH}_{3}$ & $\mathrm{R}_{1}$ : p-anisidyl \\
\hline 25 & $\mathrm{n}: 2$ & $\mathrm{R}: \mathrm{H}$ & $\mathrm{R}_{1}: p$-Chlorobenzyl \\
\hline 26 & $\mathrm{n}: 2$ & $\mathrm{R}: \mathrm{CH}_{3}$ & $\mathrm{R}_{1}: p$-Chlorobenzyl \\
\hline 27 & $\mathrm{n}: 2$ & $\mathrm{R}: \mathrm{H}$ & $\mathrm{R}_{1}: p$-toluenesulfonyl \\
\hline 28 & $\mathrm{n}: 2$ & $\mathrm{R}: \mathrm{CH}_{3}$ & $\mathrm{R}_{1}$ : p-toluenesulfonyl \\
\hline 2 & $\mathrm{n}: 2$ & $\mathrm{R}: \mathrm{H}$ & $\mathrm{R}_{1}$ : methyl phenyl sulfide \\
\hline 30 & $\mathrm{n}: 2$ & $\mathrm{R}: \mathrm{CH}_{3}$ & $\mathrm{R}_{1}$ : methyl phenyl sulfide \\
\hline 31 & $\mathrm{n}: 3$ & $\mathrm{R}: \mathrm{H}$ & $\mathrm{R}_{1}: p$-toluenesulfonyl \\
\hline 32 & $\mathrm{n}: 3$ & $\mathrm{R}: \mathrm{CH}_{3}$ & $\mathrm{R}_{1}: p$-toluenesulfonyl \\
\hline 3 & $\mathrm{n}: 3$ & $\mathrm{R}: \mathrm{H}$ & $\mathrm{R}_{1}$ : methyl phenyl sulfide \\
\hline 34 & $\mathrm{n}: 3$ & $\mathrm{R}: \mathrm{CH}_{3}$ & $\mathrm{R}_{1}$ : methyl phenyl sulfide \\
\hline
\end{tabular}

Figure 1. The structure of compounds 1-34 synthesized and evaluated as antiprotozoal agents in vitro. 
Table 1. Antiprotozoal activity of the starting terpenes dehydroabietic acid (DHA), oleanolic acid (OA), and synthetic derivatives 1-34 towards Leishmania promastigotes, Trypanosoma cruzi epimastigotes, and cytotoxicity on NCTC-Clone 929 cells. The results are presented as $\mathrm{IC}_{50}$ data in $(\mu \mathrm{g} / \mathrm{mL})$.

\begin{tabular}{|c|c|c|c|c|}
\hline \multirow[t]{2}{*}{ Compound } & \multicolumn{2}{|c|}{$\begin{array}{l}\text { Leishmanicidal Activity on } \\
\text { Promastigotes }(\mu \mathrm{g} / \mathrm{mL})\end{array}$} & \multirow{2}{*}{$\begin{array}{c}\text { Antiepimastigote Activity of } \\
\text { T. cruzi }(\mu \mathrm{g} / \mathrm{mL})\end{array}$} & \multirow{2}{*}{$\begin{array}{l}\text { NCTC-Clone } \\
929 \text { Fibroblasts } \\
(\mu \mathrm{g} / \mathrm{mL})\end{array}$} \\
\hline & L.braziliensis & L. infantum & & \\
\hline DHA & 44 & 72 & 212 & - \\
\hline Dehydroabietinol & 63 & 40 & 66 & - \\
\hline 1 & 53 & 60 & 46 & $>256$ \\
\hline 2 & $>256$ & $>256$ & $>256$ & $>256$ \\
\hline 3 & $>256$ & $>256$ & $>256$ & $>256$ \\
\hline 4 & 64 & 64 & 61 & 189 \\
\hline 5 & 218 & 193 & 223 & $>256$ \\
\hline 6 & $>256$ & $>256$ & $>256$ & $>256$ \\
\hline 7 & $>256$ & $>256$ & $>256$ & $>256$ \\
\hline 8 & $>256$ & $>256$ & $>256$ & $>256$ \\
\hline 9 & $>256$ & $>256$ & $>256$ & $>256$ \\
\hline 10 & $>256$ & $>256$ & $>256$ & $>256$ \\
\hline 11 & $>256$ & $>256$ & $>256$ & $>256$ \\
\hline 12 & $>256$ & $>256$ & $>256$ & $>256$ \\
\hline 13 & 242 & $>256$ & $>256$ & $>256$ \\
\hline 14 & $>256$ & $>256$ & $>256$ & $>256$ \\
\hline 15 & 89 & 53 & 69 & 232 \\
\hline 16 & 71 & 73 & 199 & 129 \\
\hline OA & $>256$ & $>256$ & $>256$ & - \\
\hline 17 & $>256$ & $>256$ & 252 & 196 \\
\hline 18 & $>256$ & $>256$ & $>256$ & $>256$ \\
\hline 19 & 109 & 155 & $>256$ & $>256$ \\
\hline 20 & $>256$ & $>256$ & $>256$ & $>256$ \\
\hline 21 & $>256$ & $>256$ & $>256$ & $>256$ \\
\hline 22 & $>256$ & $>256$ & $>256$ & $>256$ \\
\hline 23 & $>256$ & $>256$ & $>256$ & $>256$ \\
\hline 24 & $>256$ & $>256$ & $>256$ & $>256$ \\
\hline 25 & $>256$ & $>256$ & $>256$ & $>256$ \\
\hline 26 & $>256$ & $>256$ & $>256$ & $>256$ \\
\hline 27 & $>256$ & $>256$ & 43 & $>256$ \\
\hline 28 & $>256$ & $>256$ & 61 & $>256$ \\
\hline 29 & $>256$ & $>256$ & $>256$ & $>256$ \\
\hline 30 & $>256$ & $>256$ & $>256$ & $>256$ \\
\hline 31 & $>256$ & 128 & $>256$ & $>256$ \\
\hline 32 & $>256$ & $>256$ & $>256$ & - \\
\hline 33 & $>256$ & $>256$ & $>256$ & - \\
\hline 34 & $>256$ & $>256$ & $>256$ & - \\
\hline Pentamidine & 3.3 & 3.3 & - & - \\
\hline Benzimidazole & - & - & 15.0 & - \\
\hline
\end{tabular}

\subsection{Dehydroabietic Acid Derivatives}

The activity on T. cruzi of DHA, dehydroabietinol, and compounds 1-16 was moderate. When comparing with DHA, the effect was stronger for dehydroabietinol, with $\mathrm{IC}_{50}$ of $66 \mu \mathrm{g} / \mathrm{mL}$ compared with $212 \mu \mathrm{g} / \mathrm{mL}$ for DHA. The most active products were the derivatives $\mathbf{1}, \mathbf{4}$, and $\mathbf{1 5}$ with $\mathrm{IC}_{50}$ values of 46,61 , and $69 \mu \mathrm{g} / \mathrm{mL}$, respectively. Compound 1 has a $\mathrm{CH}_{2}$ linker between the diterpene and the triazole, while 2 ( $\mathrm{IC}_{50}>256 \mu \mathrm{g} / \mathrm{mL}$ ) bears two $\mathrm{CH}_{2}$ units in the linker. However, when the triazole presents a methyl phenyl sulfide (compounds 3 and 4 ), the effect is stronger for the compound with two $\mathrm{CH}_{2}$ units in the linker (>256 vs. $61 \mu \mathrm{g} / \mathrm{mL}$ ). The same trend was observed for compounds 15 and 16, with $\mathrm{IC}_{50}$ values of 69 and $199 \mu \mathrm{g} / \mathrm{mL}$, respectively. The most active product 15 shows two $\mathrm{CH}_{2}$ units in the linker while 16 presents four $\mathrm{CH}_{2}$ units in the linker, respectively. These results are 
showing the importance of linker length in the activity against T. cruzi in this type of compounds. Subsequent studies including linkers of different lengths would be necessary to identify the ideal chain length to obtain derivatives with potential activity against T. cruzi. Inhibition of Leishmania proliferation in vitro was tested against two promastigote strains. DHA, dehydroabietinol, and their derivatives, $1,4,15$, and 16, were the most active compounds against both species evaluated with $\mathrm{IC}_{50}$ values of $44,63,53,64,89$, and $71 \mu \mathrm{g} / \mathrm{mL}$ against L. braziliensis and 72, 40,60, 64, 53, and $73 \mu \mathrm{g} / \mathrm{mL}$ against $L$. infantum, respectively. These compounds except the derivative $\mathbf{1 6}$ were also active against T. cruzi. The same structure-activity trend discussed for T. cruzi is observed for Leishmania. When comparing the evaluated derivatives versus the reference compound (pentamidine, $\mathrm{IC}_{50}: 3.3 \mu \mathrm{g} / \mathrm{mL}$ ), a marked difference in activity against Leishmania was observed. However, pentamidine has several side effects including nephrotoxicity, so alternative drugs are still needed. The cytotoxicity of the compounds was evaluated on NCTC-Clone 929 fibroblasts. Among the evaluated derivatives only compounds $4,15,16$, and 17 showed moderate cytotoxic activity with $\mathrm{IC}_{50}$ values in the range of 129-232 $\mu \mathrm{g} / \mathrm{mL}$. With the exception of compound 17, these dehydroabietic derivatives are those that have shown the best antiparasitic activity in this study $(4,15$, and 16), so it could be deduced that the cytotoxicity is relatively non-specific, and the molecules could be acting indistinctly on the cells and the parasites.

Natural abietane diterpenes have shown interesting antiparasitic activities. For example, Samoylenko et al. [31] reported the antileishmanial activity of ferruginol and totarol against L. donovani promastigotes with $\mathrm{IC}_{50}$ values of $3.5 \mu \mathrm{g} / \mathrm{mL}$ for both compounds and $\mathrm{IC}_{90}$ values of 7.0 and $6.9 \mu \mathrm{g} / \mathrm{mL}$, respectively. Another naturally occurring abietane with antileishmanial activity is 12-methoxycarnosic acid with an $\mathrm{IC}_{50}$ value of $0.75 \mu \mathrm{M}$ against axenically grown L. donovani amastigotes. Recently, Olmo et al. [32] reported five abietane diterpenoids as candidates for treating Chagas disease. These compounds were synthesized from abietic acid, essentially all of them being dehydroabietic acid derivatives. In vitro and in vivo activity and the possible mechanism of action of the compounds were studied. In vitro trypanocidal evaluation of the compounds against different forms of the parasite showed better effects than the reference drug. Two compounds were the best candidates, being 29- and 52-fold more active than benznidazole against amastigotes forms. Additionally, they exhibit good activity in vivo and low toxicity.

In recent studies, dehydroabietic acid was treated with different amino acid in search of antiprotozoal activity [33]. The derivatives were evaluated against L. donovani amastigotes and T. cruzi amastigotes. Several of them showed good activity-in some cases, higher than the reference compound benznidazole. In continuation of this study, the same group reported the preparation of new amides, but this time starting from dehydroabietylamine [34]. The derivatives were evaluated against L. donovani and T. cruzi. The most promising compound showed $\mathrm{IC}_{50}$ values of $0.37 \mu \mathrm{M}$ and $0.6 \mu \mathrm{M}$, with a selectivity index value of 63 and 58 against L. donovani axenic amastigotes and T. cruzi, respectively. Subsequent to this work, Dea-Ayuela et al. [35] reported new dehydroabietylamine derivatives with antileishmanial activity against promastigotes of L. donovani, L. infantum, L. amazonensis, and L. guyanensis with $\mathrm{IC}_{50}$ values in the range of $2.2-46.8 \mu \mathrm{M}$.

\subsection{Oleanolic Acid Derivatives}

For the OA derivatives (compounds 17-34), only two compounds (27 and 28) showed a relevant effect on $T$. cruzi with $\mathrm{IC}_{50}$ values of 43 and $61 \mu \mathrm{g} / \mathrm{mL}$, respectively. They differ in the free (27) or methylated $\mathrm{COOH}$ function of the triterpene (28) but show the same $p$-toluensulfonyl moiety in the triazole ring. On the other hand, the results on leishmanicidal activity show that only compounds 19 and 31 have a slight effect. Compounds 19 presents activity against both L. braziliensis and L. infantum promastigotes, with $\mathrm{IC}_{50}$ values of $109 \mu \mathrm{g} / \mathrm{mL}$ and $155 \mu \mathrm{g} / \mathrm{mL}$, respectively. Compound 31 showed activity only against $L$. infantum promastigote with an $\mathrm{IC}_{50}$ of $128 \mu \mathrm{g} / \mathrm{mL}$. All other compounds should be regarded as inactive on Leishmania promastigotes $\left(\mathrm{IC}_{50}>256 \mu \mathrm{g} / \mathrm{mL}\right)$. 
Several natural pentacyclic triterpenoid such as epi-oleanolic acid, betulinic acid, and betulinaldehyde, among others display leishmanicidal activity against different Leishmania species [36,37]. Torres-Santos et al. [38] reported the antileishmanial activity of ursolic acid and oleanolic acid. Ursolic acid showed $\mathrm{IC}_{50}$ values of 5 and $27 \mu \mathrm{g} / \mathrm{mL}$, and oleanolic acid displayed $\mathrm{IC}_{50}$ values of 10 and $11 \mu \mathrm{g} / \mathrm{mL}$ against the promastigote and amastigote stage of L. amazonensis, respectively. Recently, Melo et al. [39] determined the activity of oleanolic acid against three different Leishmania species (L. braziliensis, L. amazonensis, and L. infantum). The reported leishmanicidal activity against promastigotes and amastigote shows $\mathrm{IC}_{50}$ values in the range of 30-66 $\mu \mathrm{M}$ and 38-69 $\mu \mathrm{M}$, respectively. The results differ from our study, where the $\mathrm{IC}_{50}$ values of the OA was $>256 \mu \mathrm{g} / \mathrm{mL}$. This difference can be explained by protozoal strains, isolated from different sources and the low solubility in water of OA.

Rodríguez-Hernández et al. [40] reported the synthesis and leishmanicidal activity of hederagenin derivatives prepared by click chemistry. Hederagenin is a triterpene which differs from oleanolic acid by an additional hydroxyl group at C-23. Unlike the OA derivatives reported in this paper, where esters were at the C-3 position, the Hederagenin derivatives were prepared on the carboxylic acid in C-28. Hederagenin esters and amides containing 1,2,3-triazole derivatives were evaluated against amastigote forms of L. infantum. The four additional active derivatives showed $\mathrm{IC}_{50}$ values of $2 \mu \mathrm{M}$, $9.7 \mu \mathrm{M}, 11 \mu \mathrm{M}$, and $12 \mu \mathrm{M}$.

Taking together, the synthetic strategy of coupling a diterpene (DHA) or a triterpene (OA) with a triazole using click chemistry allowed us to obtain structural diversity for structure-activity studies. Some of the derivatives presented better antiprotozoal effects than did the starting compounds, suggesting that further modifications might lead to better antiprotozoal effects for this group of compounds.

\section{Materials and Methods}

\subsection{Chemistry}

Dehydroabietic acid (DHA) was obtained from commercial rosin as described in [41]. Oleanolic acid (OA) was isolated from the aerial parts of Fabiana imbricata [42]. The triazole derivatives were prepared as described previously (Figure 1) [41,42]. Briefly, DHA was methylated with $\mathrm{CH}_{2} \mathrm{~N}_{2}$ to afford dehydroabietic acid methyl ester. Reduction of the methyl ester with $\mathrm{LiAlH}_{4}$ in $\mathrm{THF}$ gave the corresponding alcohol (dehydroabietinol). Starting from DHA and its alcohol, 16 abietane-triazole compounds were obtained using click chemistry [41]. The alkyl esters of DHA and its alcohol were prepared using $\mathrm{N}, \mathrm{N}$-dicyclohexylcarbodiimide (DCC)/ dimethylaminopyridine (DMAP) and appropriate alcohol or acid with alkyl function. The alkynyl esters were treated with different azides in $t-\mathrm{BuOH} / \mathrm{H}_{2} \mathrm{O}$ using $\mathrm{CuSO}_{4} \cdot 5 \mathrm{H}_{2} \mathrm{O}$ and sodium ascorbate to obtain the derivatives 1-16 (Figure 1).

Oleanolic acid (OA) derivatives contained 1,2,3-triazoles linked to the 3-O function and a free or methylated $\mathrm{COOH}$ function at $\mathrm{C}-28$ were prepared as reported [42]. OA was treated with the appropriate alkyne acid/DCC/DMAP to afford the alkynyl esters 17-20. The alkynyl esters and different azides were dissolved in $\mathrm{CH}_{2} \mathrm{Cl}_{2} / \mathrm{H}_{2} \mathrm{O}(1: 1)$, followed by click chemistry conditions $\left(\mathrm{CuSO}_{4} \cdot 5 \mathrm{H}_{2} \mathrm{O}\right.$ /sodium ascorbate) to afford compounds 21-34 (Figure 1).

\subsection{Antiprotozoal Assays}

For in vitro studies of T. cruzi, the clone CL-B5 was used (donated by Faculty of Pharmacy, Complutense University, Madrid, Spain). Parasites were stably transfected with the Escherichia coli $\beta$-galactosidase gene (lacZ). Epimastigotes were grown at $28^{\circ} \mathrm{C}$ in liver infusion tryptose broth (Difco, Detroit, MI, USA) with 10\% fetal bovine serum (FBS) (Gibco, Carlsbad, CA, USA), penicillin (Ern S.A., Barcelona, Spain), and streptomycin (Reig Jofré S.A., Barcelona, Spain), as described previously [20], and harvested during the exponential growth phase. Briefly, the screening assay was performed in 96-well microplates (Sarstedt, Inc., Newton, NC, USA) with cultures that had not reached the stationary 
phase. Epimastigotes were seeded at $2 \times 10^{5}$ parasites $/ \mathrm{mL}$ in $200 \mu \mathrm{L}$ growth media. The plates were then incubated with the respective compounds at $28^{\circ} \mathrm{C}$ for $72 \mathrm{~h}$; afterwards, $50 \mu \mathrm{L}$ of chlorophenol red- $\beta$-D-galactopyranoside (CPRG) solution was added, resulting in a final concentration of $200 \mu \mathrm{M}$. The plates were incubated at $37^{\circ} \mathrm{C}$ for an additional $4 \mathrm{~h}$ and then read at $595 \mathrm{~nm}$. Each concentration was tested in triplicate [21]. The efficacy of each compound was estimated by calculating the $\mathrm{IC}_{50}$ values. These values were calculated by the sigmoidal dose-response curve adjustment using the statistical software program Graph-Pad Prims 3.0 (GraphPhad, San Diego, CA, USA). Benznidazole was used as the reference drug.

Culture of L. braziliensis (MHOM/BR/75/M2904), and L. infantum (MHOM/FR/91/LEM2259V) was obtained from the Facultad de Farmacia (Universidad Complutense de, Madrid, Spain). The maintenance of the strains, the form of cultivation, and the isolation of shape promastigota were performed following the procedures described by Roldos et al. [20]. The promastigotes were grown at $22{ }^{\circ} \mathrm{C}$ in Schneider's Drosophila medium supplemented with $20 \%$ FBS. The assay was performed using a modification of a previous method [43]. Promastigotes $\left(2 \times 10^{6}\right.$ parasites/well $)$ were cultured in 96-well plastic plates. Compounds were dissolved in dimethylsulfoxide (DMSO). Different dilutions of the compounds with a final volume up to $200 \mu \mathrm{L}$ were added. After $48 \mathrm{~h}$ at $26^{\circ} \mathrm{C}, 20 \mu \mathrm{L}$ of a $2 \mathrm{mM}$ resazurin solution was added, and the oxidation-reduction was quantified at 570 and $600 \mathrm{~nm}$. The solution of resazurin was prepared at $2.5 \mathrm{mM}$ in phosphate buffered solution (PBS), pH 7.4, and filtered through $0.22 \mu \mathrm{m}$ prior to use. All tests were carried out in triplicate. Resazurin sodium salt was obtained from Sigma-Aldrich (St. Louis, MO, USA) and stored at $4{ }^{\circ} \mathrm{C}$ protected from light. The efficacy of each compound was estimated by calculating the $\mathrm{IC}_{50}$ values.

\subsection{Cytotoxicity}

The cell line used was NCTC-Clone 929, which was grown in Minimal Essential Medium (Sigma) supplemented with $10 \%$ heat-inactivated FBS, penicillin G $(100 \mathrm{U} / \mathrm{mL})$, and streptomycin $(100 \mu \mathrm{g} / \mathrm{mL})$. Cell cultures were maintained at $37^{\circ} \mathrm{C}$ in a humidified $5 \% \mathrm{CO}_{2}$ atmosphere. The procedure for cell viability measurement was evaluated with resazurin by a colorimetric method. The cells were plated in 96-microtiter plates at $3 \times 10^{4}$ cells per well in a $100 \mu \mathrm{L}$ growth medium. The cells were grown overnight at $37^{\circ} \mathrm{C}, 5 \% \mathrm{CO}_{2}$. Thereafter, the medium was removed and the compounds were added in a $200 \mu \mathrm{L}$ medium for $24 \mathrm{~h}$. After incubation, $20 \mu \mathrm{L}$ of a $2 \mathrm{mM}$ resazurin solution was added to each well. The plates were incubated for $3 \mathrm{~h}$ to allow optimal oxidation-reduction. The reduction of resazurin was determined by dual wavelength absorbance measurement at 490 and $595 \mathrm{~nm}$. Background was subtracted. Each concentration was assayed three times. Medium and drug controls were used in each test as blanks [44].

\section{Conclusions}

In the present work, 34 terpene-triazole derivatives were synthesized starting from the natural products dehydroabietic acid, dehydroabietinol, and oleanolic acid. The antiprotozoal activity of the compounds was evaluated against epimastigote forms of T. cruzi, promastigotes of L. braziliensis and L. infantum, and cytotoxicity on NCTC-Clone 929 cells. The compounds that showed moderate activity were the most active diterpene DHA, dehydroabietinol, and the derivatives 1, 4, 15, 16, 27, and 28 . The antiparasitic effect was associated with the linker length between the diterpene and the triazole in dehydroabietinol derivatives. For the oleanolic acid derivatives, a free carboxylic acid function led to better antiparasitic activity. Further preclinical studies on both protozoa could be carried out on the tissue phase of both parasites (amastigotes), as well as in vivo assays in experimentally infected mice, in order to obtain more information about their potential use of its antiprotozoal activity.

Acknowledgments: M.W.P. thanks Fondo Nacional de Desarrollo Científico y Tecnológico (FONDECYT), Chile (grant 1161092). We thank the Programas de Investigación de Excelencia Interdisciplinaria (PIEI-QUIM-BIO), Universidad de Talca, for additional financial support. Paraguayan researchers benefit from the Programa Nacional de Incentivo al Investigador (PRONII), Consejo Nacional de Ciencia y Tecnología, (CONACYT), Paraguay. 
Author Contributions: M.W.P. was responsible for the synthesis and wrote the manuscript, C.V., M.R., C.C., and A.R.d.A. carried out the biological assays, and G.S.-H. contributed with valuable discussion and revision of the manuscript.

Conflicts of Interest: The authors report no conflict of interest.

\section{References}

1. Pan American Health Organization. Health in the Americas 2007. In Regional, Scientific and Technical Publication 622; Pan American Health Organization: Washington, DC, USA, 2007.

2. World Health Organization. First WHO Report on Neglected Tropical Diseases. Working to Overcome the Global Impact Neglected Tropical Diseases; World Health Organization: Geneva, Switzerland, 2010; ISBN: 978-92-4-1564090.

3. Yamagata, Y.; Nakagawa, J. Control of Chagas disease. Adv. Parasitol. 2006, 61, 129-165. [PubMed]

4. World Health Organization. Global Health Estimates 2014 Summary Tables: DALY by Cause, Age and Sex, by WHO Region, 2000-2012. Geneva, Switzerland, 2014. Available online: http:/ /www.who.int/healthinfo/ global_burden_disease/en/ (accessed on 21 November 2016).

5. WHO. Chagas Disease (American Trypanosomiasis). Available online: http://www.who.int/mediacentre/ factsheets/fs340/en/ (accessed on 12 December 2016).

6. Senior, K. Chagas disease: Moving towards global elimination. Lancet Infect. Dis. 2007, 7, 572. [CrossRef]

7. Hotez, P.J.; Bottazzi, M.E.; Franco-Paredes, C.; Ault, S.K.; Periago, M.R. The Neglected Tropical Diseases of Latin America and the Caribbean: A Review of Disease Burden and Distribution and a Roadmap for Control and Elimination. PLoS Negl. Trop. Dis. 2008, 2, e300. [CrossRef] [PubMed]

8. Gascón, J. Epidemiology of Chagas disease in Europe and control programs in Spain. In Proceedings of the I Iberoamerican Workshop on Chagas Disease, Triatomine Vectors, T. cruzi, and Triatoma Virus, Lisboa, Portugal, 13-16 September 2010.

9. Rassi, A.; Rassi, A.; Marcondes de Rezende, J. American Trypanosomiasis (Chagas Disease). Infect. Dis. Clin. N. Am. 2012, 26, 275-291. [CrossRef] [PubMed]

10. Yeo, M.; Acosta, N.; Llewellyn, M.; Sanchez, H.; Adamson, S.; Miles, G.A.J.; Lopez, E.; Gonzalez, N.; Patterson, J.S.; Gaunt, M.W.; et al. Origins of Chagas disease: Didelphis species are natural hosts of Trypanosoma cruzi I and armadillos hosts of Trypanosoma cruzi II, including hybrids. Int. J. Parasitol. 2005, 35, 225-233. [CrossRef] [PubMed]

11. Zingales, B. Molecular epidemiology of Chagas disease: Gaps of knowledge and research priorities. Biomédica 2011, 31, 3-315.

12. De Rojas Arias, A. Status of Chagas disease in the Americas. In Laboratorios Silanes; Enfermedad de Chagas: Estrategias en la Búsqueda de Nuevos Medicamentos, 1st ed.; Cerrteto, H., Gonzalez, M., Eds.; Una Visión Iberoamericana: Col. del Valle, Mexico, 2012; Volume 1, pp. 17-34. ISBN: 978-607-95813-0-5.

13. De Mello, T.F.; Bitencourt, H.R.; Pedroso, R.B.; Aristides, S.M.; Lonardoni, M.V.; Silveira, T.G. Leishmanicidal activity of synthetic chalcones in Leishmania (Viannia) braziliensis. Exp. Parasitol. 2014, 136, 27-34. [CrossRef] [PubMed]

14. Faria, J.V.; Maurício, S.; Bernardino, A.M.R.; Becker, K.M.; Machado, G.M.C.; Rodrigues, R.F.; Canto-Cavalheiro, M.M.; Leon, L.L. Synthesis and activity of novel tetrazole compounds and their pyrazole-4-carbonitrile precursors against Leishmania spp. Bioorg. Med. Chem. Lett. 2013, 23, 6310-6312. [CrossRef] [PubMed]

15. Pinedo-Cancino, V.; Laurenti, M.D.; Kesper, N.; Umezawa, E.S. Evaluation of Leishmania (Leishmania) infantum excreted-secreted antigens for detection of canine leishmaniasis. Acta Trop. 2016, 161, 41-43. [CrossRef] [PubMed]

16. Urbina, J.; Docampo, R. Specific chemotherapy of Chagas disease: Controversies and advances. Trends Parasitol. 2003, 19, 495-501. [CrossRef] [PubMed]

17. Chiarpenello, J. Enfermedad de Chagas (Tripanosomiasis Americana). Evid. Actual Pract. Ambul. 2004, 7 , 114-119.

18. Kalil, J.; Cunha-Neto, E. Autoimmunity in Chagas disease cardiomyopathy: fullfilling the criteria at last? Parasitol. Today 1996, 12, 396-399. [CrossRef]

19. Engman, D.M.; Leon, J.S. Pathogenesis of Chagas heart disease: Role of autoimmunity. Acta Trop. 2002, 81, 123-132. [CrossRef] 
20. Roldos, V.; Nakayama, H.; Rolo, M.; Trucco, F.; Torres, S.; Vega, C.; Marrero-Ponce, Y.; Heguaburu, V.; Yaluff, G.; Go, A.; et al. Activity of a hydroxybibenzyl bryophyte constituent against Leishmania spp. and Trypanosoma cruzi: In silico, in vitro and in vivo activity studies. Eur. J. Med. Chem. 2008, 43, 1797-1807. [CrossRef] [PubMed]

21. Vega, C.; Rolón, M.; Martínez-Fernández, A.R.; Escario, J.A.; Gómez-Barrio, A. A new pharmacological screening assay with Trypanosoma cruzi epimastigotes expressing $\beta$-galactosidase. Parasitol. Res. 2005, 95, 296-298. [CrossRef] [PubMed]

22. Lepesheva, G.I. Design or screening of drugs for the treatment of Chagas disease: What shows the most promise? Expert Opin. Drug Discov. 2013, 8, 1-11. [CrossRef] [PubMed]

23. Lamim, M.; Domeneghini, L.; Rosaria, L.; Dias, S.; Kramer, L.; Regina, T.; Mascarello, A.; Steindel, M.; Augusto, R.; Carla, H.; et al. Trimethoxy-chalcone derivatives inhibit growth of Leishmania braziliensis: Synthesis, biological evaluation, molecular modeling and structure-activity relationship (SAR). Bioorg. Med. Chem. 2011, 19, 5046-5052.

24. WHO. Research and Development to Meet Health Needs in Developing Countries; Report of the Consultative Expert Working Group on Research and Development: Strengthening Global Financing and Coordination; Financing and Coordination; World Health Organization: Geneva, Switzerland, 2012.

25. Hussain, H.; Al-Harrasi, A.; Al-Rawahi, A.; Green, I.R.; Gibbons, S. Fruitful decade for antileishmanial compounds from 2002 to late 2011. Chem. Rev. 2014, 114, 10369-10428. [CrossRef] [PubMed]

26. Porta, E.O.J.; Carvalho, P.B.; Avery, M.A.; Tekwani, B.L.; Labadie, G.R. Click chemistry decoration of amino sterols as promising strategy to developed new leishmanicidal drugs. Steroids 2014, 79, 28-36. [CrossRef] [PubMed]

27. Diogo, E.B.T.; Dias, G.G.; Rodrigues, B.L.; Guimarães, T.T.; Valença, W.O.; Camara, C.A.; de Oliveira, R.N.; da Silva, M.G.; Ferreira, V.F.; de Paiva, Y.G.; et al. Synthesis and anti-Trypanosoma cruzi activity of naphthoquinone-containing triazoles: Electrochemical studies on the effects of the quinoidal moiety. Bioorg. Med. Chem. 2013, 21, 6337-6348. [CrossRef] [PubMed]

28. Da Silva, E.N.; Menna-Barreto, R.F.S.; Pinto, M.d.C.F.R.; Silva, R.S.F.; Teixeira, D.V.; de Souza, M.C.B.V.; de Simone, C.A.; de Castro, S.L.; Ferreira, V.F.; Pinto, A.V. Naphthoquinoidal [1-3]-triazole, a new structural moiety active against Trypanosoma cruzi. Eur. J. Med. Chem. 2008, 43, 1774-1780. [CrossRef] [PubMed]

29. Carvalho, I.; Andrade, P.; Campo, V.L.; Guedes, P.M.M.; Sesti-Costa, R.; Silva, J.S.; Schenkman, S.; Dedola, S.; Hill, L.; Rejzek, M.; Nepogodiev, S.A.; et al. "Click chemistry" synthesis of a library of 1,2,3-triazole-substituted galactose derivatives and their evaluation against Trypanosoma cruzi and its cell surface trans-sialidase. Bioorg. Med. Chem. 2010, 18, 2412-2427. [CrossRef] [PubMed]

30. De Andrade, P.; Galo, O.A.; Carvalho, M.R.; Lopes, C.D.; Carneiro, Z.A.; Sesti-Costa, R.; de Melo, E.B.; Silva, J.S.; Carvalho, I. 1,2,3-Triazole-based analogue of benznidazole displays remarkable activity against Trypanosoma cruzi. Bioorg. Med. Chem. 2015, 23, 6815-6826. [CrossRef] [PubMed]

31. Samoylenko, V.; Dunbar, D.C.; Gafur, Md.A.; Khan, S.I.; Ross, S.A.; Mossa, J.S.; El-Feraly, F.S.; Tekwani, B.L.; Bossealaers, J.; Muhammad, I. Antiparasitic, nematicidal and antifouling constituents from Juniperus berries. Phyther. Res. 2008, 22, 1570-1576. [CrossRef] [PubMed]

32. Olmo, F.; Guardia, J.J.; Marin, C.; Messouri, I.; Rosales, M.J.; Urbanová, K.; Chayboun, I.; Chahboun, R.; Alvarez-Manzaneda, E.J.; Sánchez-Moreno, M. Prospects of an alternative treatment against Trypanosoma cruzi based on abietic acid derivatives show promising results in Balb/c mouse model. Eur. J. Med. Chem. 2015, 89, 683-690. [CrossRef] [PubMed]

33. Vahermo, M.; Krogerus, S.; Nasereddin, A.; Kaiser, M.; Brun, R.; Jaffe, C.L.; Yli-Kauhaluoma, J.; Moreira, V.M. Antiprotozoal activity of dehydroabietic acid derivatives against Leishmania donovani and Trypanosoma cruzi. Med. Chem. Comm. 2016, 7, 457-463. [CrossRef]

34. Pirttimaa, M.; Nasereddin, A.; Kopelyanskiy, D.; Kaiser, M.; Yli-Kauhaluoma, J.; Oksman-Caldentey, K.M.; Brun, R.; Jaffe, C.L.; Moreira, V.M.; Alakurtti, S. Abietane-type diterpenoid amides with highly potent and selective activity against Leishmania donovani and Trypanosoma cruzi. J. Nat. Prod. 2016, 79, 362-368. [CrossRef] [PubMed]

35. Dea-Ayuela, M.A.; Bilbao-Ramos, P.; Bolás-Fernández, F.; González-Cardenete, M.A. Synthesis and antileishmanial activity of C7- and C12-functionalized dehydroabietylamine derivatives. Eur. J. Med. Chem. 2016, 121, 445-450. [CrossRef] [PubMed] 
36. Camacho, M.D.R.; Mata, R.; Castaneda, P.; Kirby, G.C.; Warhurst, D.C.; Croft, S.L.; Phillipson, J.D. Bioactive compounds from Celaenodendron mexicanum. Planta Med. 2000, 66, 463-468. [CrossRef] [PubMed]

37. Sauvain, M.; Kunesch, N.; Poisson, J.; Gantier, J.C.; Gayral, P.; Dedet, J.P. Isolation of leishmanicidal triterpenes and lignans from the amazonian liana Doliocarpus dentatus (Dilleniaceae). Phytother. Res. 1996, 10, 1-4. [CrossRef]

38. Torres-Santos, E.C.; Lopes, D.; Oliveira, R.R.; Carauta, J.P.P.; Falcao, C.A.B.; Kaplan, M.A.C.; Rossi-Bergmann, B. Antileishmanial activity of isolated triterpenoids from Pourouma guianensis. Phytomedicine 2004, 11, 114-120. [CrossRef] [PubMed]

39. Melo, T.S.; Gattass, C.R.; Soares, D.C.; Cunha, M.R.; Ferreira, C.; Tavares, M.T.; Saraiva, E.; Parise-Filho, R.; Braden, H.; Delorenzi, J.C. Oleanolic acid (OA) as an antileishmanial agent: Biological evaluation and in silico mechanistic insights. Parasitol. Int. 2016, 65, 227-237. [CrossRef] [PubMed]

40. Rodríguez-Hernández, D.; Barbosa, L.C.A.; Demuner, A.J.; de Almeida, R.M.; Fujiwara, R.T.; Ferreira, S.R. Highly potent anti-leishmanial derivatives of hederagenin, a triperpenoid from Sapindus saponaria L. Eur. J. Med. Chem. 2016, 124, 153-159. [CrossRef] [PubMed]

41. Pertino, M.W.; Verdugo, V.; Theoduloz, C.; Schmeda-Hirschmann, G. Synthesis and antiproliferative activity of some novel triazole derivatives from dehydroabietic acid. Molecules 2014, 19, 2523-2535. [CrossRef] [PubMed]

42. Pertino, M.W.; Lopez, C.; Theoduloz, C.; Schmeda-hirschmann, G. 1,2,3-Triazole-substituted oleanolic acid derivatives: Synthesis and antiproliferative activity. Molecules 2013, 18, 7661-7674. [CrossRef] [PubMed]

43. Mikus, J.; Steverding, D. A simple colorimetric method to screen drug cytotoxicity against Leishmania using the dye Alamar Blue. Parasitol. Int. 2000, 48, 265-269. [CrossRef]

44. Rolón, M.; Seco, E.M.; Vega, C.; Nogal, J.J.; Escario, A.; Gómez-Barrio, A.; Malpartida, F. Selective activity of polyene macrolides produced by genetically modified Streptomyces on Trypanosoma cruzi. Int. J. Antimicrob. Agents 2006, 28, 104-109. [CrossRef] [PubMed]

Sample Availability: Samples of the compounds 1-34 are available from the authors.

(C) 2017 by the authors. Licensee MDPI, Basel, Switzerland. This article is an open access article distributed under the terms and conditions of the Creative Commons Attribution (CC BY) license (http:/ / creativecommons.org/licenses/by/4.0/). 